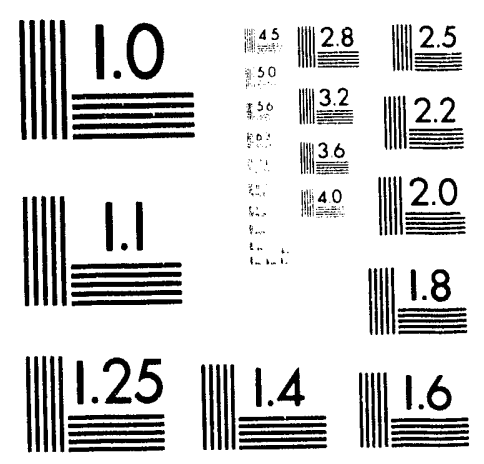



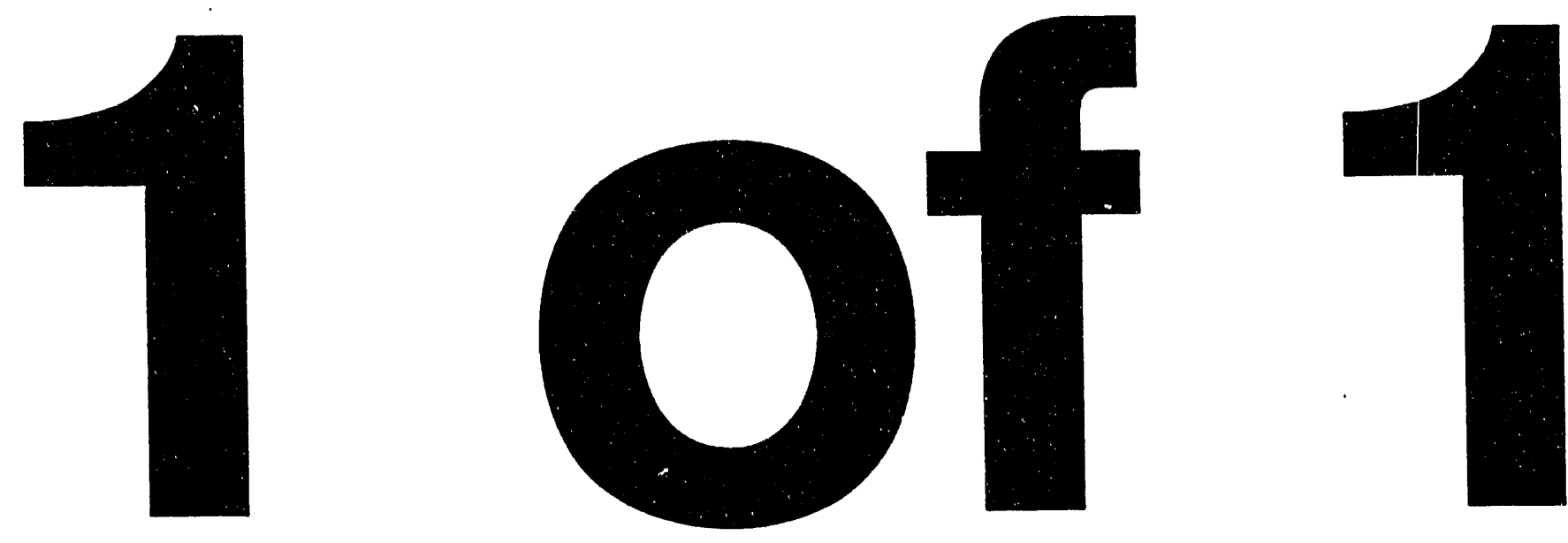


\title{
Photocathode Performance Measurements for the SLC Polarized Electron Gun*
}

\author{
C. L. Garden, E. W. Hoyt, D. C. Schultz, H. Tang \\ Stanford Linear Accelerator Center \\ Stanford, CA 94309, USA
}

\section{Abstract}

A low-voltage test system is used to qualify various III-V semiconductor materials as photocathodes for the SLC. The system features a load lock to introduce samples, high pumping speed, a sensitive residual gas analyzer, and an infrared temperature detector. Heat cleaning, cesiation, and oxidation procedures have been studied to optimize cathode activation for achieving an optimum NEA surface. VGF GaAs, MBE-grown AlGaAs, MBE GaAs layered on AlGaAs, and MOCVD GaAsP cathodes with different active layer thicknesses and doping concentrations have been tested for quantum efficiency and lifetime. New higher. polarization strained-layer GaAs on GaAsP photocathrdes have also been tested. Results and operational experience are discussed.

\section{INTRODUCTION}

The cathode test system (CTS) was established in August 1990, for materials qualification of different III$\mathrm{V}$ semiconductor photocathodes with a quick turnaround time, and to test different activation procedures in an environment that closely simulates the Polarized Electron Source (PES) Gun [1]. Experience gained here is used to maximize quantum efficiency $(\mathrm{QE})$ and $Q E$ lifetime, and aid in photcathode choice in the PES Gun. Materials come from different suppliers [8], and vary in structure, doping level, and dopant. This system is intended to compare the $\mathrm{QE}$ of different materials, but is not equipped to measure polarization. A new system that will also measure polarization is under development. See Figure 1 for an overview of the CrS.

\section{SYSTEM COMPONENTS}

The chamber vacuum level is monitored with a residual gas analyzer (RGA) that has mass range of 0 $200 \mathrm{AMU}$ and is sensitive to partial pressures of $10^{-13}$ Torr[2]. Cathode temperature (above $450^{\circ} \mathrm{C}$ ) is measured with an infrared temperature detector specially designed for work with GaAs [3]. An emissivity value of 0.7 for GaAs is used, which was calibrated by observing the congruent evaporation of $\mathrm{GaAs}$ at $663^{\circ} \mathrm{C}$ [4]. The temperature measuremerits are accurate to $\pm 5^{\circ} \mathrm{C}$.

There are two different cesium sources on the CTS: a set of channel cesiators [5] and a SLAC-built effusion cell cesiator. No difference between the performance (peak QEs achievable) of the two was observed, but the

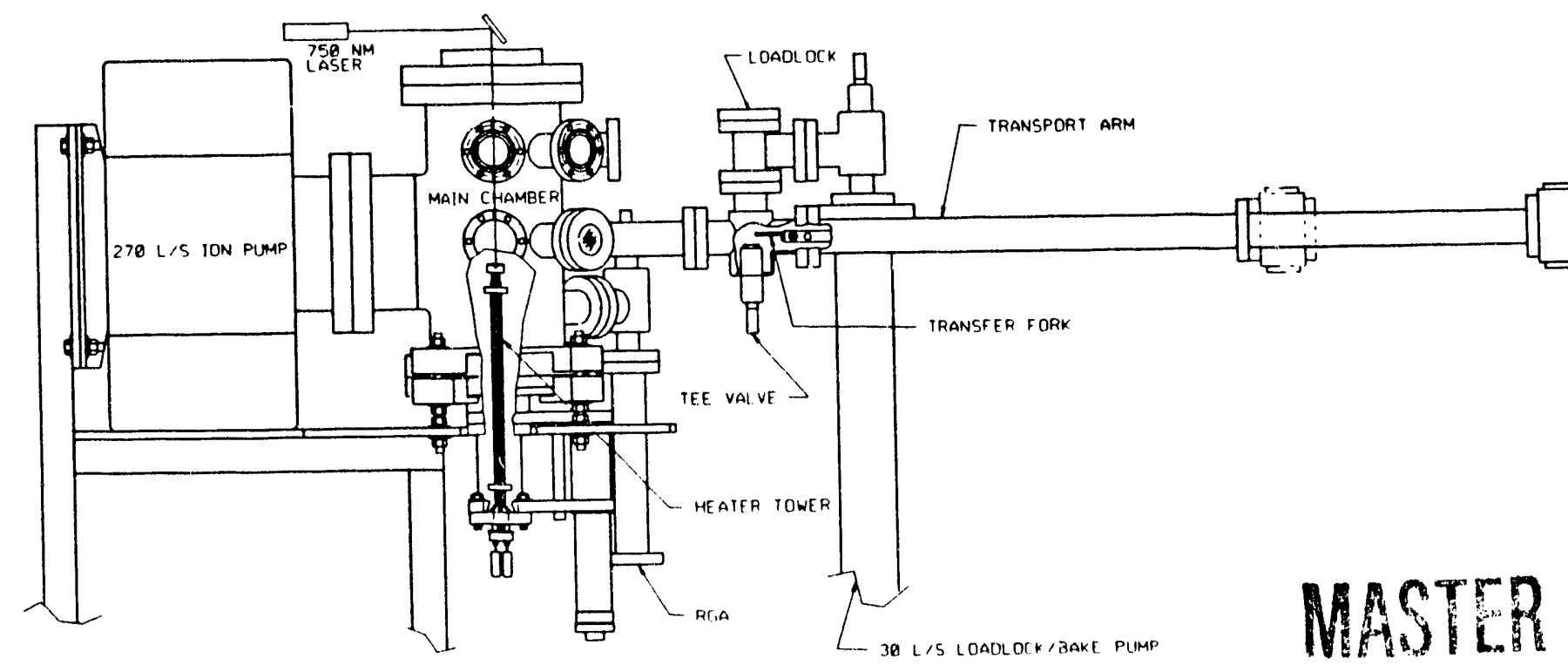

Figure 1. Cathode Test System.

" Work supported by Department of Energy contract DE-AC03-76SFO0515. 
channels are much simpler to use. The channels heat up and cool down rapidly, giving much greater control of the amount of cesium deposited.

The load-lock (and bake) pump is a thirty-l/s ion pump. There is also a twenty-l/s ion pump used to pump out the $\mathrm{NF}_{3}$ lines.

$\mathrm{QE}$ is monitored using a $750 \mathrm{~nm}$ diode laser, and occasionally a $633-\mathrm{nm}$ helium-neon laser. $\mathrm{QE}$ versus wavelength data is taken using a white light and a series of $10-\mathrm{nm}$ bandwidth interference filters. The extraction voltage on the cathode is $-132 \mathrm{~V}$, supplied by a battery box. The electrons are collected by a wire loop anode one in ch above the cathode.

Individual components were pre-baked to $450^{\circ} \mathrm{C}$. The entire system has been baked several times, initially to $1600^{\circ} \mathrm{C}$ and later to $250^{\circ} \mathrm{C}$. Following bake the total pressure is typically $5 \times 10^{-11}$ Torr. The spectrum is dominated by hydrogen, with a partial pressure of 2 to 3 $\times 10^{-12}$ of CO. Figure 2 shows a typical RGA spectrum after a bake.

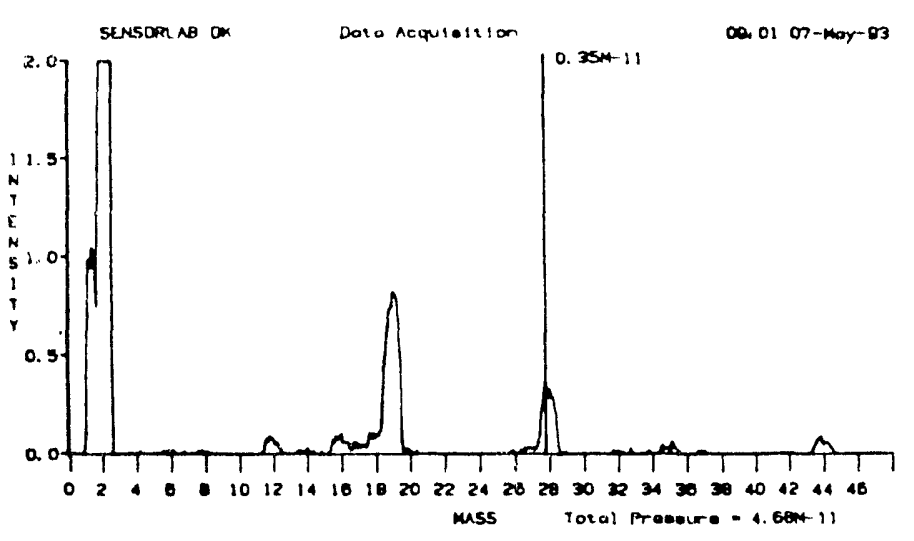

Figure 2. RGA spectrum after bake.

\section{SAMPLE PREPARATION}

Cathode materials are shipped overnight in a $\mathrm{N}_{2}$ atmosphere and are waxed to a glass cover inmediately upon receipt. The glass cover facilitates cutting the wafers with a diamond wire saw (into $18-22-\mathrm{mm}$ diameter discs), and protects the surface from contamination until use. The wax and glass cover are removed in four Pyrex beakers of boiling semiconductor grade trichloroethane, then the wafer is rinsed with semiconductor-grade methanol and blown dry with nitrogen.

VGF GaAs cathodes are then etched for ten seconds in a 4:1:1 solution of semiconductor-grade sulfuric acid, hydrogen peroxide, and de-ionized water. They are rinsed with de-ionized water and semiconductor-grade methanol and blown dry with nitrogen. All beakers and tools used to prepare cathode materials ar? Teflon to reduce the possibility of contamination.
Manufacturers add a $50-00 \AA$ arsenic cap to the thin active-layer MBE grown structures, as these can not be etched before they are used. The arsenic cap layer is removed by heat cleaning in the system. The same procedure is used in preparing cathodes for the SLC injector.

\section{LOAD-LOCK OPERATION}

Cathodes are installed through a small volume (1/2 liter) load-lock (see Figure 1). The view port on the top of the load-lock volume is removed and a photocathode on a molybdenum tray is lowered onto the seat of the closed tee valve. During this operation the load-lock is purged with 2-3 psi positive pressure of dry $\mathrm{N}_{2}$. The top view port is then replaced, and the load lock is roughed down using a turbo pump.

Pressure is low enough to switch to the thirty-l/s ion pump in about thirty minutes. To transfer the cathode into the main chamber, the tee valve on the load-lock area is opened, lowering the cathode to where it can be picked up by a transfer fork and brought into the main chamber. The transfer fork is on a long magnetically coupled arm [6]. When the fork is moved, a pressure rise due to gas desorption along the bearing of the arm is seen, and pumps out almost immediately. There is no rise in the main chamber pressure after a cathode transfer is completed. It takes thirty minutes to install the cathode onto the heater tower, after which the tee valve to the load lock is closed.

The cathode rests on a molybdenum tray during transport and when installed, this molybdenum tray rests on the heater tower. Figure 3 shows a close-up view of the cathode on the heater tower, and the positions of the anode ring and cesiators.

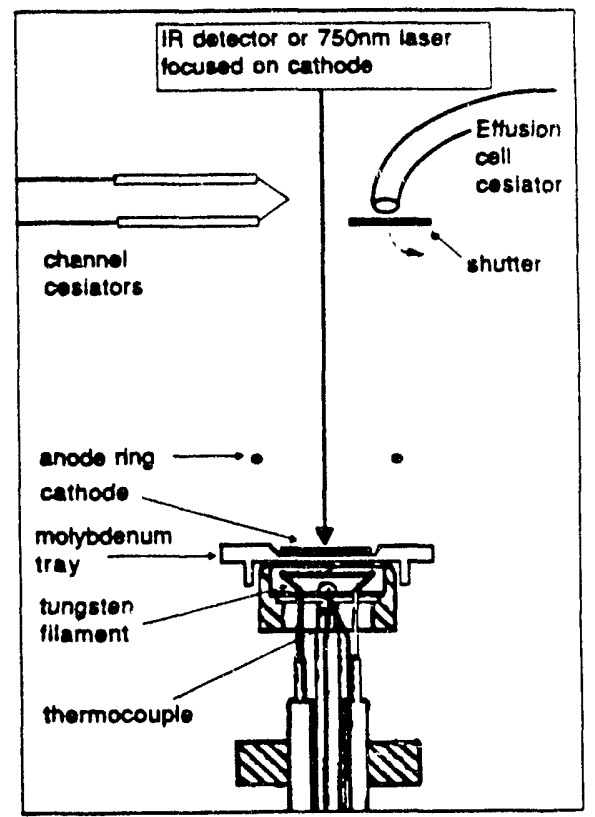

Figure 3. Close-up of cathode on heater tower, showing cesiators and anode ring. 


\section{TYPIC A , ACTIVATION}

The typical activation cycle is as follows. The cathode is heated to $600{ }^{\circ} \mathrm{C}$ for one hour. Cesium is added (thiree minutes at five amps on two $17-\mathrm{mm}$ channel cesiators). The temperature is ramped up to 640 ${ }^{\circ} \mathrm{C}$ in thirty seconds, and the power is cut as scron as $640^{\circ} \mathrm{C}$ is reached. The cathode is allowed to cool one hour, until the cathode temperature is $30^{\circ} \mathrm{C}$ or cooler. Using a 750-nm diode laser to monitor the photocurrent, cesium is added (between four and five amps on the channel cesiators, depending on their age) until the photocurrent peaks, then $\mathrm{NF}_{3}$ co-deposition is begun. The level of $\mathrm{NF}_{3}$ is adjusted to maintain a positive slope. For optimal $\mathrm{NF}_{3}$ deposition a $1 \times 10^{10}$ Torr partial pressure (sum of mass 33,52 , and 71 peak heights) is used, with cesium channels at four to five amps. The NEA layer deposition takes about one hour.

\section{ACTIVATION EXPERIMENTS}

The photocathode is heat cleaned at high temperature for 60 minutes. Heat cleaning to very high temperature is essential for attaining high QE's. Heat cleaning :o $600^{\circ} \mathrm{C}$ is much $(300$ percent better than $500^{\circ} \mathrm{C}$, and $620^{\circ} \mathrm{C}$ is somewhat $(10-30$ percent) better than $600^{\circ} \mathrm{C}$. Better $\mathrm{QE}$ (by about 10 percent) was obtained by adding some cesium near the end of the heat cleaning when the heat cleaning temperature is $600^{\circ} \mathrm{C}$.

\section{SUMMARY OF RESULTS}

Peak QE results for various cathode materials are summarized in Table 1. QEs as high as 14 percent at $750 \mathrm{~nm}(20$ percent at $633 \mathrm{~nm})$ have been obtained for GaAs and GaAsP. The results depend somewhat on chamber history, the laser power used (influencing electron desorption rate), and the number of previous activations of that cathode. Results using different cathodes cut from the same wafer can vary 2 percent in $\mathrm{QE}$.

Electron polarization of these photocathode materials is measured as $\geq 40$ percent, except for the strained GaAs material, which gives electron polarization 280 percent [7].

\section{REFERENCES}

[1] "The Polarized Electron Gun for the SLC," D. C. Schultz et al., Proc. of the Third European Part. Acc. Conf., Berlin(1992) 1029.

[2] V.G. Quadrupoles, model MSL200D5NUT, through Fisons, Danvers MA. [3] MODLINE $V$ Series, operates at $950 \mathrm{~nm}$, IRCON Inc., Niles, IL

[4] B. Goldstein et al., Surface Science 57 (1976) 733.

[5] SAES Getters, Colorado Springs, CO.

16] MDC Vacuum Components, Hayward, CA.

[7] T. Marayuma et al., Phys. Rev. B 46 (1992) 4261; and H. Aoyagi et el., Phys. Lett. A 167 (1992) 415.

[8] Photocathode Vendors:

AXT, American Crystals Technology, Dublin, CA. SPIRE, Spire Corporation, Bedford, MA. EPI, Epitaxial Products International, Ltd., Cardiff, UK.

NSI, Northeast Semiconductor, Inc., Ithaca, NY. UCB , University of California at Berkeley, Berkeley, CA. QED, Quantum Epitaxial Designs, Bethlehem, PA.

\begin{tabular}{|c|c|c|c|c|c|}
\hline \multirow[b]{2}{*}{ Material } & \multirow[b]{2}{*}{$\mathrm{QE}$} & \multirow[b]{2}{*}{ Vendor } & \multicolumn{3}{|c|}{ Active Layer } \\
\hline & & & Composition & Thickness & Doping \\
\hline VGF GaAs & $13.90 \%$ & $A X T$ & GaAs & $635.0 \mu \mathrm{m}$ & $\begin{array}{l}2 E+19 Z n \\
5 E+18 Z n\end{array}$ \\
\hline $\begin{array}{c}\text { Strained GaAs } \\
\text { GaAsP }\end{array}$ & $0.85 \%$ & SPIRE & GaAs on GaAsP & $\begin{array}{l}0.2 \mu \mathrm{m} \\
2.0 \mu \mathrm{m}\end{array}$ & \\
\hline GaAsP & $\begin{array}{l}14.40 \% \\
13.00 \%\end{array}$ & $\begin{array}{l}\text { EPI } \\
\text { EPI }\end{array}$ & $\mathrm{GaAs}_{87} \mathrm{P}_{13}$ & $4.0 \mu \mathrm{m}$ & $2 E+19 Z n$ \\
\hline AlGaAs & $7.10 \%$ & NES & $\mathrm{GaAs}_{.88} \mathrm{Al}_{.12}$ & $1.5 \mu \mathrm{m}$ & $6 \mathrm{E}+18 \mathrm{Be}$ \\
\hline AlGaAs & $6.00 \%$ & UCB & GaAs $.88 \mathrm{Al}_{.12}$ & $0.3 \mu \mathrm{m}$ & $5 E+18 B e$ \\
\hline AlGaAs & $6.10 \%$ & QED & $\mathrm{GaAs}_{.88} \mathrm{Al}_{.12}$ & $0.3 \mu \mathrm{m}$ & $1 \mathrm{E}+19 \mathrm{Be}$ \\
\hline AlGaAs & $5.10 \%$ & NES & GaAs. ${ }_{88} \mathrm{Al}_{12}$ & $0.3 \mu \mathrm{m}$ & $1 \mathrm{E}+19 \mathrm{Be}$ \\
\hline
\end{tabular}

Table 1: Summary table of results for various materials. 

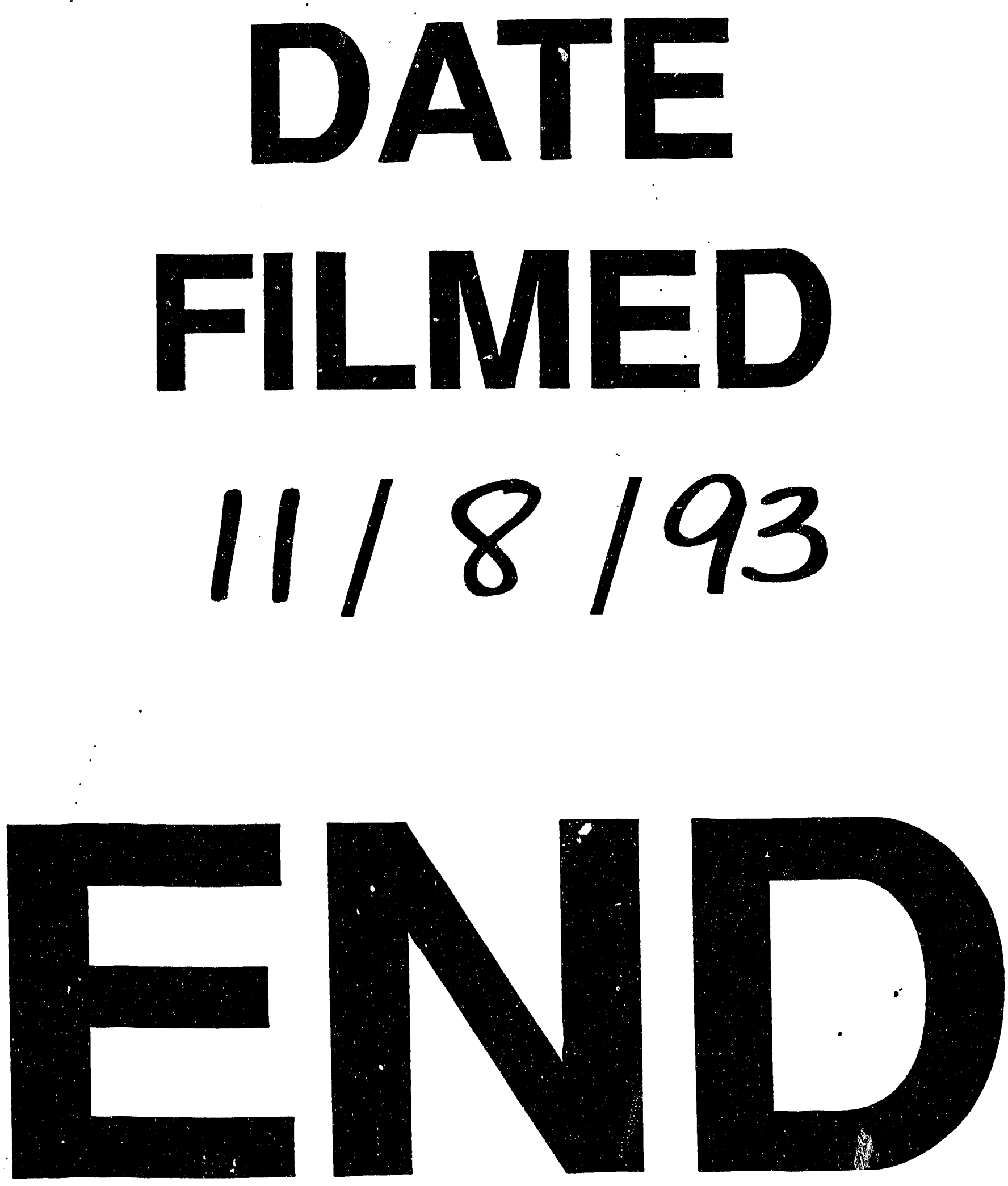


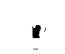

